\title{
"MORIR POR DAR LUZ": NOTAS SOBRE LA MATERNIDAD EN LA LITERATURA Y LA BRECHA
}

\author{
Mónica-Ramón Ríos \\ Pratt Institute \\ Nueva York, Estados Unidos \\ mriosvas@pratt.edu
}

Como si el título ya prefigurara su efecto sobre una sociedad conservadora, La brecha (1961) de Mercedes Valdivieso proporciona un examen sobre los límites impuestos a la mujer a mediados del siglo XX y las maneras en cómo traspasarlos. Aquellos límites, que llamo, siguiendo las primeras páginas de la novela, "el destino biológico de la mujer", eran asuntos considerados sectoriales, pero que de a poco se movían a la esfera pública común debido a las discusiones sobre las leyes de divorcio, herencia, paternidad y el resto de las escuetas regulaciones sobre el ámbito de la reproducción. Cuando se publicó esta novela en 1961, hacía poco más de una década que se le había dado derecho a voto a las mujeres en Chile y el país cruzaba un periodo, como nos cuenta Julieta Kirkwood, en el que las luchas feministas fueron relevadas por otras más generales, sectorizando esas demandas específicas ${ }^{1}$. En ese contexto, donde los asuntos de mujeres estaban subsumidos a los de la familia ${ }^{2}$, Mercedes Valdivieso perfila un personaje instalando una brecha

\footnotetext{
Apunta Julieta Kirkwood que el periodo de los años veinte vio un auge de movimientos feministas en todos los sectores sociales de Chile, que crecieron alrededor de la demanda por el voto, hasta su consecución en 1949. Sumadas en calidad de ciudadanas, sin embargo, los sectores políticos sociales amplios "absorbe[n] la dimensión sufragista-feminista [...] por razones diversas las mujeres disuelven sus instituciones y pasan a integrar, por separado, los diversos departamentos femeninos que se ofrecían a sus opciones ideológicas" (56). Sus conflictos aparecían, pues, "resueltos por la gran resolución del "conflicto de clases fundamental"" (28).

Es expresivo que, incluso en la propuesta de Constitución que estaba en proceso de redactarse durante el gobierno de la Unidad Popular, "la mujer" quedó paralizada bajo el
} 
entre una existencia-mujer y los mandatos de género. La importancia de esta novela radica, por lo menos en parte, en que prefiguró las posibles rebeldías del destino de cierto tipo de mujer, un ideal de mujer fabricado en la república independiente en ceñido pacto entre Estado e Iglesia, que expropió a la mujer de clase alta de bienes, destino, subjetividad y de su cuerpo, y la metió en la casa. Aquella mujer, descrita por Valdivieso en los primeros capítulos con tempranos atisbos de rebeldía, estaba destinada a pasar desde el hogar paterno y los veranos en la hacienda familiar al colegio de monjas en preparación para el matrimonio, presa del patriarcado del salario y la maternidad.

Durante la última década y junto a un nuevo despertar feminista, la maternidad reapareció como un asunto literario con diferentes inflexiones y no únicamente en las letras chilenas. Mientras preparo este ensayo, leo cinco notas incluidas en el newsletter de la publicación estadounidense Literary $H u b$ sobre recientes libros que tratan de maternidades ${ }^{3}$, que me llevan a otros artículos donde la crítica Parul Sehgal habla de la maternidad como un nuevo tópico de la narrativa de las mujeres en ámbitos comerciales. En esos libros, la autoría y la autoridad se construyen sobre la experiencia de haber parido y criado a otro ser humano, un rol que a veces es deseado y que en otras ocasiones se vive como un desajuste con la vida intelectual. La maternidad aparece, pues, no solo atado a los géneros autoficcionales o incluso confesionales, sino como una paradoja, la paradoja de ser, como describe Maggie Nelson en su novela The Argonauts (2016), una de las transformaciones más radicales del cuerpo de la mujer, pero que se constituye como un territorio ocupado de discursos conservadores (65).

Una paradoja similar -y el incipiente atisbo de prestarle nuevos lenguajeses la que aparece en libros como Diario de quedar embarazada (2016), de Claudia Apablaza, y en algunos cuentos de Estampida (2019), de Bernardita

acápite "La mujer, la familia y el niño".

"On the Complexities of Motherhood: A Reading List", de Avni Doshi, del 4 de febrero de 2021; "What Will the Literature of Motherhood Look Like After COVID?", de Ashley Nelson Levy, del 12 de mayo de 2021; "On the Relationship Between Motherhood and Madness in Victorian Literature", de Kyra Wilder, del 21 de abril de 2021; "Finding Time to Write About Motherhood... While Parenting During a Pandemic", de Pragya Agarwal, del 3 de junio de 2021; y de Parul Sehgal "Mothers of Invention. A group of authors finds new narrative possibilities in parenthood" de un número de Bookforum del 2015 y "In a Raft of New Books, Motherhood From (Almost) Every Angle" aparecido en el New York Times del 24 de abril de 2018. 
Bravo. Para ambas podríamos utilizar el término "maternidades líquidas" con que Lorena Amaro distingue la aparición de este asunto literario en el siglo XXI chileno: "De lo que hoy se trata es de que haya tantas maternidades como madres, y parte del juego del sistema neoliberal consiste en ofrecer a sus consumidores la posibilidad de elegir una experiencia maternal dentro de un vasto mercado disponible" (25). En esta descripción de Amaro, la única red de resonancias para la creación de discursos alternativos sobre la maternidad las prestaría el mercado, donde se barajan hegemónicas imágenes raciales y de clase, por no decir únicamente de género, sobre la mujer que se transforma y cuida. En palabras de la ensayista Jacqueline Rose, "como si lo máximo a lo que las madres pudieran aspirar fuese a servir de decorado al neoliberalismo" (8).

Bajo aquella mirada, la oración "Morir por dar luz" (28) con que la protagonista sin nombre de Mercedes Valdivieso en La brecha describe su "angustia demoledora, aterradora" (25) sobre el destino biológico de la mujer ubica la siguiente alternativa: se es mujer - profesional y libre- o se es madre -destino prescrito por los guiones de la nación heterosexual ${ }^{4}$-. Esta lógica binaria inscribe nuevamente el aspecto biológico como centro de la lucha feminista, provocando que el único interlocutor posible frente a los discursos sobre la maternidad sea el patriarcado, estando a favor o en contra de atar la maternidad a la familia y a la nación. Frente a esto me pregunto, ¿es posible una maternidad que hable otro lenguaje, que describa las transformaciones radicales de los cuerpos para pensar el colectivo?

En esta nota, me interesa indagar de manera ensayística sobre la maternidad como tópico literario y cultural central de la lucha feminista, considerando La brecha como punto de inflexión de un cierto feminismo que llamaré burgués. Mi objetivo es modelar otros discursos sobre la maternidad que no aten la lucha feminista al destino biológico. En efecto, más que indagar, este ensayo quiere poner en acción el feminismo como potencia generadora de lenguajes que describan otras formas de vida ya experimentadas e incluso transformadas en literatura, pero que encuentran insuficientes resonancias en la crítica entendida aquí, siguiendo a Sylvia Wynter (239), como una

\footnotetext{
Más sobre el mandato de la heterosexualidad en el artículo "Traffic in Women Notes on the 'Political Economy' of Sex" (1975), de Gayle Rubin, y el libro La Nación Heterosexual. Análisis del discurso jurídico y el régimen heterosexual desde la antropología de la dominación (2013), de Ochy Curiel.
} 
práctica de desciframiento capaz de afectar la esfera de lo común. Lucha material y discursiva clave para el feminismo histórico y el actual, la maternidad pone de relieve el problema de la relación entre la sociedad en general y les sujetes y sus cuerpos. Aquella relación ha sido explorada por varias escritoras chilenas, representando la maternidad en relación con sus contextos: como discurso de acceso a la esfera pública con sus marcas de clase, género, raza y origen nacional (por ejemplo, Rosario Orrego ${ }^{5}$ ); como espacio de reflexión y resistencia crítica a adscribir a los modelos dictados por el orden republicano capitalista heteropatriarcal (por ejemplo, en los varios tomos de Alborada, de Inés Echeverría); como resistencia al uso del cuerpo de la mujer como imagen patrio (pienso en el espectro que protagoniza Poema de Chile (1967), de Gabriela Mistral); como resistencia al lugar subordinado de la mujer (en los cuentos de Marta Brunet); como lugar de crítica hacia la violencia (dictatorial, heteropatriarcal, como en esas maternidades abyectas que describe Amaro en los cuentos de Pía Barros y Diamela Eltit); y durante el neoliberal siglo XXI, como sitio para repensar la familia, la subjetividad o el acceso a los productos de la profesión. Estos discursos, explorados ampliamente por la crítica, enhebran la maternidad a la experiencia bajo las varias dictaduras que se alojan en el cuerpo de la mujer, creando particiones falsas dentro del movimiento literario feminista (por ejemplo, entre las escritoras que tienen hijos y las que no, o entre el feminismo y el transfeminismo). Así, la maternidad surge como un espacio poblado del lenguaje del otro que niega la precisión a la escritura sobre el cuerpo y sus potencialidades políticas.

Aquí ensayo otros discursos sobre la maternidad con el objetivo de abrir caminos para pensar un feminismo futuro, sumando mi voz a la más reciente ola de crítica transfeminista ${ }^{6}$. Propongo utilizar la conocida metodología feminista de examinar los campos semánticos reificados como binarismos y/u oposiciones para descubrir cómo la maternidad puede describir una

madre".

La escritora Rosario Orrego publicó sus primeros escritos con el seudónimo "Una

Como describe Sayak Valencia, el transfeminismo es una "herramienta epistemológica que no se reduce a la incorporación del discurso transgénero al feminismo, ni se propone como una superación de los feminismos. Antes bien, se trata de una red que considera los estados de tránsito de género, de migración, de mestizaje, de vulnerabilidad, de raza y de clase, para articularlos como herederos de la memoria histórica de los movimientos sociales de insurrección" (31). 
continuidad entre (dar) vida y (dar) muerte, dos elementos que articulan poéticas y políticas sobre los cuerpos, la reproducción y los cuidados. Sin negar que la maternidad es clave para el análisis feminista debido a esa curiosa carga que nos obliga a volver a la realidad biológica y a su control biopolítico, busco una genealogía literaria y cultural que ponga al centro la maternidad militante y la maternidad no biológica, sacando así la discusión de la experiencia individual heredada de la construcción nacional y el capitalismo, y ubicándola en vez como parte de un tejido social que revoluciona los mandatos de género, heterosexualidad y monogamia.

\section{PARIR Y ABORTAR}

El embarazo en La brecha se experimenta como una prisión. La protagonista lo describe como un fracaso, un dejar de pertenecerse (Valdivieso 21) que continúa el mandato de género que obliga a las mujeres a pasar de la casa paterna a la del esposo. La novela describe el espacio de la maternidad mediante los estrechos mecanismos del marianismo católico de la suegra y la severidad de la madre. Así, para la protagonista, "el embarazo era un nudo de angustia y desolación", una rebeldía que la aproximaba al padre idealizado, ambos "un poco hijo del Diablo" (Valdivieso 24-5). Dar a luz resulta una especie de liberación -"sola con mi propio cuerpo", escribe Valdivieso- para luego decidir "Haré lo necesario para impedir que esto se vuelva a repetir. Nunca más" (Valdivieso 33-4). En el registro directo, incluso en las reminiscencias, de cómo la maternidad es un hito impuesto en la vida de esa mujer, La brecha surge como una intervención a un contexto limitado por vectores estéticos y éticos de clase. Delineada contra un trasfondo católico particular a la clase alta chilena de mediados de siglo, esa subjetividad sueña con una libertad idealizada en Europa y su cultura -la promesa del padre interrumpida por su muerte es viajar al continente del que se considera heredero-y que no considera el trabajo ni la sobrevivencia como parte de su horizonte político.

Pero hay un momento en la novela en que la transparencia del lenguaje desaparece. En el capítulo VIII, la protagonista está nuevamente embarazada y se hace un aborto. Narrado en apenas una página, sobre los eventos se estrechan y complican los vectores valóricos instalados en el relato del primer embarazo: 
el espanto era una garra de dedos sangrientos sobre mi vientre; pensé en el castigo, en la muerte.

¿Qué iba a hacer?

Y allá estaba unas horas después. El calmante corrió por las venas insensibilizando el cuerpo, pero la mente se mantenía alerta dentro de su caja adormecida. En el cielo blanco de la pieza, la luz de la lámpara que venía del piso reflejaba un monstruo negro que se movía con lentitud. El dolor era la lucha de la especie por sobrevivir y lloraba por mis ojos. Quebraba yo en esos momentos todos los cánones, las normas; me convertía en una réproba que merecía castigo; el horror transpiraba en mi frente, en mis manos, en mi cuello; corría, mojaba mis cabellos, llegaba hasta la camilla. Estaba sola con la muerte en mí. Hice un esfuerzo para hablar:

-Un poco más de calmante, quiero dormir.

Perdí la conciencia. (Valdivieso 68).

Este extracto presenta particularidades estilísticas que lo diferencian del resto del libro, donde prima una narración mayoritariamente exenta de tropos literarios. En esta cita, en cambio, el lenguaje del registro realista resulta insuficiente y, por lo tanto, indica un sitio aún inexplorado y de potencialidad expresiva, una experiencia difícil de desentrañar bajo coordenadas estéticas prestadas. A diferencia de la narración del embarazo y del parto de los capítulos anteriores, en este pasaje la protagonista describe con detalle la transformación del cuerpo, un cuerpo que no solo quiere evitar ser madre de nuevo, sino que, sobre todo y conscientemente -al principio del pasaje describe que tiene "la mente alerta" (ibid.)-, escenifica simultáneamente un quiebre y una continuidad con las convenciones alojadas en su destino biológico. En el extracto, el cuerpo aparece revestido culturalmente de manera tal que las descripciones corporales se transmutan en imágenes y símbolos sostenidos por el espectro de la muerte y el oprobio, bosquejando una antimadre contraria al trasfondo ideológico antes descrito, donde la maternidad es pureza. Así, el realismo con que Valdivieso describe la habitación blanca se interrumpe con la imagen de un monstruo negro, y el desgarro que siente este cuerpo durante un aborto muta hiperbólicamente en el aullido de la especie. Asimismo, los efectos físicos de un cuerpo experimentando una intervención corporal extrema en una situación de ilegalidad transforman la transpiración en horror, y el dolor físico, en una ruptura con los cánones de lo aceptable. En cada una de estas oraciones, el cuerpo, el lenguaje y el aparataje ideológico aparecen como una indisoluble entidad contra la cual emerge una nueva subjetividad. 
Dicho de otro modo, en este aborto también se pare algo, y ese algo requiere de un nuevo lenguaje.

Aquí hallo una potencia, semilla de existencias que no circulan en la esfera pública hegemónica, y cuya representación indica un afuera de ese sujeto "mujer" que quiere representar el feminismo burgués. De ese lugar, emana una cadena de sentidos donde el poder específico asociado a la biología de la mujer -el "dar vida"- no se opone al "dar muerte", ya sea como control natal o como ejercicio revolucionario. En efecto, el feminismo accionado de manera radical reorganiza el campo semántico que separa parir y abortar de tal manera que coexistan bajo una forma de vida alternativa a los guiones prestablecidos. Traigo aquí algunos ejemplos.

En la película Portrait de la jeune fille en feu (2019), dirigida por Céline Sciamma, el aborto de la joven Sophie es presentado de manera sugerente, enmarcando cinematográficamente varias posicionalidades y miradas, a excepción de aquella que organiza "el aborto" en oposición a "dar a luz". En la casa de la matrona, especialista en asistir a las mujeres en partos y abortos, Sophie se recuesta sobre una cama donde hay dos bebés. La directora elide las partes sangrientas de la intervención. En vez, en un primer plano picado, vemos la cara de Sophie tendida retorciéndose de dolor, mientras en la esquina superior del plano uno de los bebés le toma la mano. En la escena, fuera de campo, están las dos protagonistas que han acompañado a Sophie, la pintora Marianne y su amante y modelo Héloïse. Ambas observan el procedimiento, registrando todos los detalles, los mismos que, en la secuencia posterior mientras están cuidando a Sophie, le permiten a Héloïse posar la escena del aborto para que Marianne la dibuje. Aquella escena instala otra lógica semántica relacionada con una mirada conscientemente no masculina, y que emerge, en la Italia del siglo XVII donde se ubica la acción, en una isla poblada únicamente por mujeres. Exentas de esa autoridad que regula la relación entre mujeres y mediante las manos expertas que dan a luz, crían y abortan, haciendo desaparecer ese aparataje ideológico que ata el cuerpo de las mujeres a decidir entre la reproducción obligada o la interrupción del embarazo oprobioso. De la mano de la matrona y de la mano de un bebé, parir y abortar emergen como parte de un mismo saber.

En una charla titulada "Armed Mothering", del 8 de abril de 2021, la profesora Jasmin Young relató, entre otras, la siguiente escena: el 7 de abril de 1972, Ida McCray, una activista estadounidense de 19 años asociada a The Republic of New Africa y al Black Panther Party además de mantener 
vínculos con el Black Liberation Army ${ }^{7}$, secuestró un avión junto a su novio con el objetivo de escapar de las autoridades estadounidenses. En sus brazos llevaba a su bebé de cinco meses, una escopeta y un revólver. Tal como la mujer que cruza los puntos de seguridad franceses con la bomba escondida en un coche en La batalla de Argel (1966), o como las mujeres en la Argentina de la resistencia que se ponían panzas prominentes para acomodar las armas, McCray utilizó las expectativas culturales de la modestia y la fragilidad asociadas al embarazo y la maternidad para escapar de las autoridades que criminalizaban la intersección de justicia racial con la de género. Para McCray, la maternidad en ningún momento representaba una suspensión de la voluntad revolucionaria ni una limitación a su accionar político, en cuyo horizonte estaba la muerte como destino posible. Por el contrario, tal como argumenta Young, las mujeres presionaron a los movimientos revolucionarios negros a incluir el género como parte del programa de transformación social, comprendiendo asimismo la demanda por considerar, en particular en poblaciones vulnerables o que están en lucha, la maternidad como un acto subversivo ${ }^{8}$.

En la autobiografía donde describe su experiencia como prisionera política, Assata Shakur incluye el momento en que la maternidad se transforma en parte de su programa. A pesar de que en varias ocasiones Shakur había precisado su poco interés en la maternidad, al salir de su aislamiento la posibilidad se instala en su horizonte: “¿Quién cuidaría a mi bebé? Pensé en lo que Simba había dicho sobre cómo nuestros hijos son la esperanza del futuro en un mundo como este". Y luego agrega: "No voy a dejar que estos parásitos, estos opresores, estos puercos racistas y codiciosos me hagan matar a mis hijos en mi mente antes de que nazcan. Voy a vivir y a amar a Kumau, y si un bebé nace de esa unión, voy a regocijarme. Porque nuestros hijos son nuestro futuro, y creo en el futuro y en la fuerza y la integridad de nuestra lucha" (92-93, la traducción es mía) ${ }^{9}$. Young, que comenta este

\footnotetext{
Los registros de circulación sobre el involucramiento de McCray con estos movimientos es poco claro. Sin embargo, en las historias orales registradas por Young, McCray hace explícita esas conexiones.

Como explica Young, la maternidad efectivamente fue utilizada como arma política por las fuerzas que querían desbaratar los movimientos de liberación, por ejemplo, al no proporcionar cuidado y salud a las mujeres prisioneras embarazadas o durante el parto, o amenazar durante los interrogatorios con la integridad de aquellos que estaban a su cuidado.

Este es el pasaje original: "Who would take care of my baby? I thought about what Simba has said about our children being our hope for the future. I had never wanted a child.
} 
pasaje en su charla, detalla que efectivamente Shakur queda embarazada y da a luz mientras está en prisión -no en una prisión simbólica como la del feminismo burgués, sino en prisión efectiva-. Shakur llama a su bebé Kakuya, que significa, nos recuerda Young, "esperanza para el futuro", una verdadera afirmación sobre la visión revolucionaria de Shakur que incluye el amor y la maternidad militante ${ }^{10}$ como herramientas políticas en comunidades azotadas por violencias sostenidas.

En estas descripciones, la maternidad surge como un acto tan político como hacer una revolución o pensar la sexualidad fuera y más allá de los mandatos de la colonialidad de género, como un sistema de género moderno/ colonial (Lugones 189, 198), que se nos revela también atado a estas otras invenciones modernas: clase y raza. La narrativa emancipatoria de Valdivieso no requeriría tantos deslindes como los que presenté si la protagonista anónima de La brecha no quisiera representar, con sus demandas particulares, a todas las mujeres. Por cierto, Valdivieso inserta un paratexto al inicio de la novela, donde afirma que el nombre del personaje "podría ser el de cualquier mujer de nuestra generación" (7). Si en esa falta de nombre aparece la voluntad femenina como programa político en rebeldía, esa emancipación no encuentra alianzas con el objetivo de transformar la sociedad entera, como sí lo hicieron antes Alexandra Kollontai, Emma Goldman o las mujeres que publicaron en el diario feminista La Alborada a principios del siglo XX en Chile. Por el contrario, aquella mujer sin nombre resulta ser la aparición en el campo nacional, la actualización, de un nuevo tipo de mujer ya presente en las urbes del mundo, y, por lo tanto, de un feminismo hegemónico; una mujer que se emancipa del matrimonio (a través del divorcio, aunque no necesariamente de la soltería o del amor lésbico), del patriarcado del salario (a través de la adquisición de una profesión, desestimando que las mujeres trabajadoras siempre realizaron trabajos manuales) y del destino biológico (a través de una planificación familiar legítima pero ilegal, cuyo acceso está asociado

[...] And i'm [sic] not letting these parasites, these oppressors, these greedy racist swines make me kill my children in my mind before they are even born. I'm going to live and i'm to love Kumau, and, if a child comes from that union, i'm going to rejoice. Because our children are our futures and $i$ believe in the future and in the strength and righteousness of our struggle" (92-93).

10 Similar al caso de Vicky Walsh, como lo relata María Moreno en Oración: Carta a Vicki y otras elegías politicas (2018). Comento su interesante argumento sobre la militancia como parte de la herencia materna en otro artículo "Los nombres del futuro". 
a privilegios de clase y a la experiencia cisgénero). Es decir, se trata de un abrirse camino actualizando a "la mujer" a los nuevos escenarios de la sociedad burguesa. La efectividad de esa representación, materializada en las varias ediciones de la novela en pocos meses, también determina los límites de $L a$ brecha como programa feminista, trayectoria similar al feminismo de algunas escritoras actuales que también utilizan un "nosotras" para representar, desde sus demandas particulares, a un colectivo de suyo complejo y abigarrado.

\section{MATERNIDADES NO BIOLÓGICAS}

La mujer perfilada en La brecha asume como parte de su programa el ejercicio de la libertad individual. En las primeras páginas de la novela, aquella libertad está presentada como la permisividad dada a su hermano Andrés, que puede salir a jugar a su arbitrio, mientras la protagonista debe quedarse dentro de la casa aprendiendo a zurcir bajo el ojo vigilante de una abuela severa. Contrasto la representación de este ejercicio manual, asociado a cierta feminidad de clase alta que se prepara para el trabajo doméstico no remunerado, con el tejido que realiza la protagonista del cuento "Soledad de la sangre" de Marta Brunet. Mediante ese tejido, una mujer pobre casada con un hombre avaro, autoritario y poco atractivo atisba una libertad posible en el dinero producto de su trabajo y en la adquisición de un fonógrafo. Además, contrasto ese zurcido con que Valdivieso simboliza la división de las esferas públicas y privadas al zurcido ejecutado por la Loca del Frente en la novela Tengo miedo torero (2001), de Pedro Lemebel, y que la inserta a pesar suyo en asuntos públicos, al ser su clienta principal la esposa del dictador. Mientras en La brecha el zurcido se convierte en la herencia del segundo sexo, en Tengo miedo torero el zurcido es testigo del vínculo afectivo y del cuidado proporcionado por Rana, su madre travesti. Si la novela de Mercedes Valdivieso sitúa la emergencia de la subjetividad burguesa emancipada de los mandatos del género mediante brechas, al intersectar el género con otras experiencias de opresión (como la clase y los géneros no binarios) emerge un sujeto (porque está sujeto, entre otras cosas, a la historia que hereda como territorio y posicionalidad) capaz de establecer una existencia en el tránsito entre lados y capaz de transformar esos vectores en una consciencia no tanto oposicional, como sí divergente.

Así aparece la maternidad de Tía Encarna en los primeros capítulos de la novela Las malas (2019), de Camila Sosa Villada. Esta travesti vieja, dueña de una pensión donde se refugian las jóvenes travestis del Parque Sarmiento, 
es "madre adoptiva", "madre de todos los monstruos"11, con un "instinto materno [...] teatral, pero [que] dominaba su carácter como si fuera auténtico". Tía Encarna "[e]xageraba como una madre, controlaba como una madre, era cruel como una madre" (cap. 1). La estructura de la novela contrasta la relación amenazante que la protagonista tuvo con su familia biológica con la que sostiene con su familia adoptiva en la casa de Tía Encarna. Esa mujer, escribe Sosa Villada, "[n]os defendía de la policía, nos daba consejos cuando nos rompían el corazón", "nos había enseñado a resistir, a defendernos, a fingir que éramos amorosas personas castigadas por el sistema". En efecto, "podía pasar una noche en vela sentada en una comisaría hasta lograr sacar del calabozo a alguna de nosotras, y era igualmente capaz de pasarse un día entero tratando de extirpar algún virus de nuestro cuerpo o algún pelo encarnado en el bigote" (cap. 1 y 2).

Asimismo, la pulsión maternal de Tía Encarna es parte fundamental de la acción de la novela. En el primer capítulo, de noche en el parque, las travestis oyen llantos que angustian a Tía Encarna. En su búsqueda en el parque, Tía Encarna encuentra a un bebé en una escena descrita en clara alusión al parto, pero un parto que se desenvuelve en un escenario impropio, cruzado por sexo, sangre, peligro policíaco, el abandono, el hambre y el llamado ético de cuidar al otro, uno donde Tía Encarna da a luz y es partera. La escena se describe así: entre "[z]anjas, abismos, arbustos que lastiman, borrachos masturbándose. [...] Las putas, las parejas calientes, los levantes fortuitos, aquellos que logran encontrarse en ese bosque improvisado [...], el Parque es como un vientre de gozo" (cap. 1). Y luego continúa:

Mucha hambre y mucha sed. Eso se siente en el clamor del bebé y es la causa de la tribulación de La Tía Encarna, que se adentra en el bosque con desesperación porque sabe que en algún lugar hay un niño que sufre. [...]

Encarna se acerca a las canaletas donde se esconden las putas cuando ven acercarse las luces de la policía y por fin lo encuentra. Unas ramas espinosas cubren al niño. Llora con desesperación, el Parque parece llorar con él. La Tía Encarna se pone muy nerviosa, todo el terror del mundo se le prende a la garganta en ese momento.

El niño está envuelto en una campera de adulto, una campera inflable 
verde. Parece una lora con la cabeza calva. Cuando intenta sacarlo de su tumba de ramas se clava espinas en las manos y las pinchaduras comienzan a sangrar, tiñen las mangas de su blusa. Parece una partera metiendo las manos dentro de la yegua para extraer al potrillo. (cap. 1).

Esta maternidad no biológica emerge de una necesaria función social comúnmente marginada como asunto de reproducción, pero que es central para personas y comunidades que viven, más que a las sombras del Estado, en plena rebeldía con sus órganos. En efecto, la maternidad que supura Encarna viene en un cuerpo golpeado, con cicatrices y moretones, testigo de una vida de violencias, amores y transformaciones corporales. A eso apunta Sosa Villada cuando escribe: "Eso que sucede en esa casa es complicidad de huérfanas" (cap. 2). Y tal vez por eso mismo el reconocimiento de carácter ético "en algún lugar hay un niño que sufre" (cap. 1) condensa cierto aspecto fundamental para entender una forma de vida distinta a esa que se condensa como libertad individual. Las maternidades no biológicas de las comunidades de mujeres trans abren un proceso desidentificatorio con las imágenes que vinculan, en cierto feminismo burgués de segunda ola, la función de cuidado al de la prisión. Extrañándola de su destino biológico, la maternidad se delinea como aquella función social que instala el afecto como atributo fundamental de la vida, propio de la sustancia que aglutina humanos.

\section{EN LA BRECHA}

No me parece raro que la novela de Sosa Villada invoque a Gabriela Mistral en su epígrafe, una mujer queer que adoptó y cuidó niños en la vida y en la ficción. En Poema de Chile, la voz poética -también en transición, esta vez entre la vida y la muerte-, al atestiguar la muerte de la madre de un niño atacameño, Tolomí, lo adopta. Viajan juntos por los paisajes de Chile, evitando los centros administrativos, diseñando una cartografía alternativa a la del Estado-nación como sitio y materialización del olvido materno. A través de esta voz maternoespectral, el niño va aprendiendo la configuración del paisaje: el nombre de flores, hierbas, animales y paisajes bajo sus denominaciones cotidianas, las mismas que la fantasma conoció de boca de su madre. La tierra se transforma en "madre nuestra.../ viva y eterna, recia madre/ señora nuestra, joven abuela" (259). Nada más lejos de ese "Morir por dar luz" (28) de Valdivieso. En la novela en décimas de Mistral, se va tramando una herencia que desborda el 
vínculo materno-filial en su versión conservadora. Es arma del futuro posible que sin duda nos obliga a reconsiderar las relaciones con madres y abuelas que en La brecha se descartan de antemano como subyugadas. Porque esas madres también tienen cuerpos marcados de cicatrices.

Las visiones entregadas aquí presentan la maternidad como una función social que supera, aunque no excluye, la realidad biológica, cuyo reconocimiento es fundamental para una reorganización del valor que damos a las actividades de reproducción en general, y que incluyen, como describe Tithi Bhattacharya en la introducción al volumen Social Reproduction Theory (1-2), acceso a salud, vivienda, alimentación y educación; al transporte, la movilidad, incluidas las calles y el diseño urbano, el esparcimiento, la integridad física, el bienestar psíquico, la deliberación política, la vida espiritual y, en fin, como escribió Karl Marx, todo lo que permite que esa trabajadora llegue a la puerta de la fábrica y -agregamos- de la oficina, de la universidad, los hospitales, las casas particulares, el teléfono, la pantalla y el teclado con la energía suficiente para realizar su trabajo. Estas experiencias de la maternidad como acto subversivo, que revierte las formas en que la colonialidad y el capitalismo en su actual forma quita valor a la vida, han sido escritas. Sin embargo, nos falta hacerlas resonar con precisión para que de letra adquieran cuerpo. Hoy todavía tenemos pendiente lo que las mujeres que editaron el diario feminista La Alborada en 1906, en cuyo número 19 incluyeron una editorial titulada "En la brecha" donde se llama a "empuña[r] la pluma para defender nuestro sexo, que por tanto tiempo yace esclavo de ridículos y falsos prejuicios" con el objetivo de "[marchar] resueltas al porvenir" (87). De una brecha a otra, en esos otros tránsitos y herencias repasados aquí -las maternidades militantes y las maternidades no biológicas-, podemos reconsiderar los varios roles que las mujeres ponen en acción para transformar una existencia que nos mata (con su violencia directa o con sus prisiones) en una vida que valga la pena vivir.

\section{BIBLIOGRAFÍA}

Amaro, Lorena. "Maternidades 'líquidas': feminismos y narrativas recientes en Chile”. Revista Chilena de Literatura 101, 2020, pp. 13-39.

Anzaldúa, Gloria. Borderlands/La Frontera. San Francisco, Aunt Lute, 2012.

Apablaza, Claudia. Diario de quedar embarazada. Santiago, Ediciones B, 2017.

Bhattacharya, Tithi. "Introduction: Mapping Social Reproduction Theory". Social Reproduction Theory. Tithi Battacharya y Lise Vogel (eds.), Londres, Pluto Press, 2018, pp. 1-20. 
Bravo, Bernardita. Estampida. Santiago, Cuneta, 2019.

Brunet, Marta. "Soledad de la sangre”. Soledad de la sangre. Montevideo, Arca, 1967.

Constitución chilena de 1973. Propuesta del Gobierno de la Unidad Popular. Santiago, Sangría Editora, 2013.

"En la brecha". La Alborada 19, 11 de noviembre de 1906. Torcer la palabra. Escrituras obrero-feministas, compilado por el Colectivo Catrileo-Carrión, Santiago, Tiempo Robado Editoras, 2018.

Goldman, Emma. Marriage and Love. Nueva York, Mother Earth, 1911.

"The Tragedy of Women's Emancipation". Nueva York, Mother Earth, 1911.

KIRKwood, Julieta. Ser política en Chile: las feministas y los partidos. Santiago, FLACSO, 1986.

Lugones, María. "Heterosexuality and the Colonial/Modern Gender System". Hypatia 22, $\mathrm{N}^{\circ} 1,2007$, pp. 186-209.

Nelson, Maggie. The Argonauts. Nueva York, Melville House, 2015.

Rose, JACQUeLINE. Madres: un ensayo sobre la crueldad y el amor. Madrid, Siruela, 2018.

Shakur, Assata. Assata. An Autobiography. Chicago, Lawrence Hill Press, 2001.

Sosa Villada, Camila. Las malas. Buenos Aires, Tusquets, 2019.

Valdivieso, Mercedes. La brecha. Pittsburgh, Latin American Literary Review Press, 1986.

VAlencia, SAYAK. "El transfeminismo no es un generismo". Pléyade 22, 2018, pp. 27-43.

Young, JASMIN. "Reimagining the Black Past: Jasmin Young, 'Armed Mothering"”. YouTube, Milbauer Symposium, consultado el 21 de noviembre de 2021, disponible en: https:// www.youtube.com/watch?v=_pXNpZWkKc0

Wynter, Sylvia. "Rethinking 'Aesthetics': Notes towards a Deciphering Practice". Ex-iles: Essays on Caribbean Cinema. Mbye Cham (ed.), Trenton, NJ, Africa World Press, 1992. 